\title{
$A b$ Initio prediction of mycobacteriophages protein structure and function
}

\author{
Chiraag D Kapadia, Claire A Rinehart ${ }^{*}$
}

From 12th Annual UT-ORNL-KBRIN Bioinformatics Summit 2013

Buchanan, TN, USA. 22-24 March 2013

\section{Background}

Mycobacterium smegmatis is a soil bacterium. Over 448 mycobacteriophages specific for $M$. smegmatis have been sequenced and grouped into clusters of related genomes based on the similarity of their products and genome organization. Only $20 \%$ of mycobacteriophage genes have known function, as predicted by protein sequence level alignments [1].

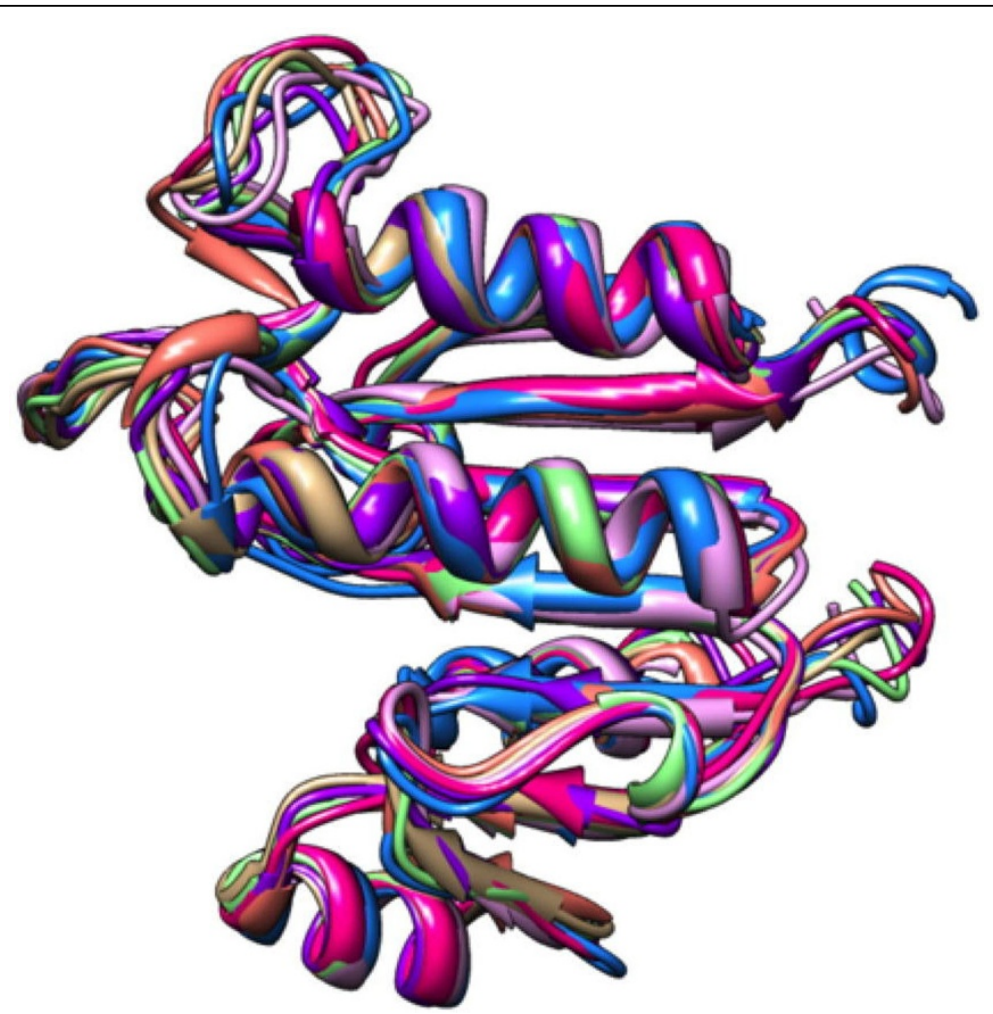

Figure 1 Seven predicted pham 6714 structures superimposed into a single model matching methyltransferase structures. PDB files were rendered using UCSF Chimera (http://www.cgl.ucsf.edu/chimera/). Proteins include MeeZee gp 78, JN243856.1; Backyardigan gp 74, JF704093.1; and ShiLan gp 70, JN020143.1

* Correspondence: claire.rinehart@wku.edu

Department of Biology, Western Kentucky University, Bowling Green, KY, 42101, USA 


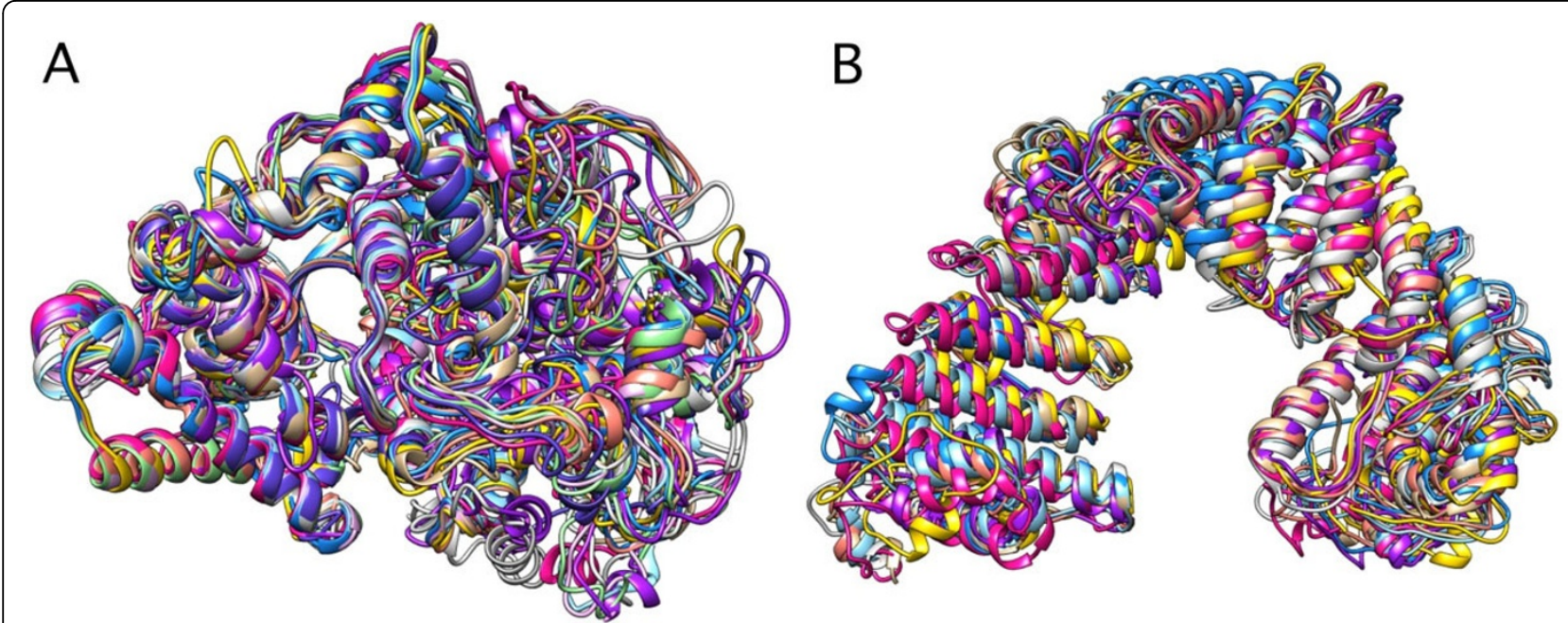

Figure 2 Ten predicted pham 2789 structures superimposed in two possible models matching either a neutral endopeptidase (A) or an importin protein (B). PDB files were rendered using UCSF Chimera (http://www.cgl.ucsf.edu/chimera/). Proteins include Ava3 gp 250, JQ911768.1; Rizal gp 242, EU826467.1; and Pio gp 260, JN699013.1

\section{Materials and methods}

Genes that are grouped together using BLAST at the protein sequence level have been assembled into loose groupings called phams [2]. The phagesdb.org/phams database contains the protein sequences organized by phams. From these data we used ab initio folding, using I-TASSER [3], to predict the structure of multiple phams across numerous mycobacteriophage clusters. Predicted models were grouped into structural families based upon RMSD scores from pairwise comparisons. Models from two structural families per pham were submitted to COFACTOR [4], which finds the best structural homologies to proteins in the PDB library and returns the matching structures along with GO terms, EC numbers and active site information.

\section{Results}

Based on COFACTOR output, we were able to suggest functions for the genes in each respective pham examined. Two notable results: 1) pham 6714 is predicted to be a methyltransferase (Figure 1), and 2) pham 2789 is predicted to be either a neutral endopeptidase (Figure 2a) or an importin protein (Figure 2b). These predicted functions will need to be confirmed experimentally.

Published: 22 October 2013

\section{References}

1. Hatfull GF: Mycobacteriophages: genes and genomes. Annu Rev Microbiol 2010, 64:331-356.

2. Cresawn SG, Bogel M, Day N, Jacobs-Sera D, Hendrix RW, Hatfull GF: Phamerator: a bioinformatics tool for comparative bacteriophage genomics. BMC Bioinformatics 2011, 12:395.
3. Roy A, Kucukural A, Zhang Y: I-TASSER: a unified platform for automated protein structure and function prediction. Nature Protocols 2010, 5(4):725-738.

4. Roy A, Yang J, Zhang Y: COFACTOR: An accurate comparative algorithm for structure-based protein function annotation. Nucleic Acids Res 2012, 40(Web Server issue):W471-W477.

doi:10.1186/1471-2105-14-S17-A10

Cite this article as: Kapadia and Rinehart: $A b$ Initio prediction of mycobacteriophages protein structure and function. BMC Bioinformatics 2013 14(Suppl 17):A10.

\section{Submit your next manuscript to BioMed Central} and take full advantage of:

- Convenient online submission

- Thorough peer review

- No space constraints or color figure charges

- Immediate publication on acceptance

- Inclusion in PubMed, CAS, Scopus and Google Scholar

- Research which is freely available for redistribution 